\title{
FDA Manufacturer Evaluation Method Code Hierarchy
}

National Cancer Institute

\section{Source}

National Cancer Institute. FDA Manufacturer Evaluation Method Code Hierarchy. NCI

Thesaurus. Code C91800.

Terminology that represents methods of evaluation used by the CDRH with respect to reporting Medical Device events. 